\title{
Research on Innovation and Development of Modern Leisure Agriculture and Rural Tourism in Beipiao
}

\author{
Min Wang1, Fuqiu Wang² \\ ${ }^{1}$ School of Marxism, Sichuan University of Arts and Sciences, Dazhou, China \\ ${ }^{2}$ School of Marxism, Zunyi Medical University, Zunyi, China \\ Email:wangmin2000703@163.com,wenlifuqiu@126.com
}

How to cite this paper: Wang, M., \& Wang, F. Q. (2020). Research on Innovation and Development of Modern Leisure Agriculture and Rural Tourism in Beipiao. Modern Economy, 11, 1544-1551. https://doi.org/10.4236/me.2020.119110

Received: August 8, 2020

Accepted: September 21, 2020

Published: September 24, 2020

Copyright $\odot 2020$ by author(s) and Scientific Research Publishing Inc. This work is licensed under the Creative Commons Attribution International License (CC BY 4.0).

http://creativecommons.org/licenses/by/4.0/

\begin{abstract}
The vigorous development of characteristic leisure agriculture has further broadened the development space of rural agriculture and organically combined agricultural products and services. This not only beautifies the rural environment, but also makes the landscape construction of the countryside show results. This paper will take the development of leisure agriculture in Beipiao area as an example to explore the development trend and predicament of leisure agriculture in poor areas and optimize the existing management ideas and models, so as to drive the open, intensive and diversified development of leisure agriculture.
\end{abstract}

\section{Keywords}

Leisure Agriculture, Rural Tourism, Innovation and Development

\section{Introduction}

In recent years, leisure agriculture has been booming in China, which has led to huge industry reform in rural areas and profound ideological transformation of rural residents, and also provided a feasible guidance for the development of urban and rural economic integration. Leisure agriculture, as a new type of agricultural production and management form, uses the rural agriculture, rural areas, rural human resources and rural life scenes, let tourists have an in-depth understanding of the rural panorama and tourism experience, improve the quality of tourism, but also can increase the income of farmers, promote better and faster development of rural areas. The development trend of modern leisure agriculture is increasingly pay attention to build differentiated experience atmosphere, 
guide the consumer taste, and improve service levels. The development of leisure agriculture in Beipiao City has certain expansion space and influence, but there are certain bottlenecks and problems need to solve. Beipiao city, a county-level city directly under the jurisdiction of the province, is now in charge of Chaoyang City. It is located in the west of Liaoning province, bordering Fuxin in the east, Nanyi County in the west, Chaoyang in the west, And Naiman Banner and Aohan in the north, with an area of about 4500 square kilometers. The territory of the main river for the Daling River, belongs to the hilly region, known as "seven mountains, a beach, two fields" said. Beipiao city has a typical temperate arid and semi-arid climate, with annual rainfall less than $500 \mathrm{~mm}$, which is called "the ninth drought in ten years". As a result, agriculture here developed very slowly.

Therefore, Beipiao City needs to be based on its own advantages, promotes their own tourism brand, actively expand domestic and international cooperation space, publicizes the advantages of Tourism, form their own distinctive characteristic industry, and promotes the "gold absorption" of Beipiao in domestic and foreign tourist cities in order to innovate the high level operation of rural tourism.

\section{The Current Situation of Innovation and Development of Beipiao Leisure Agriculture}

The development of leisure agriculture not only needs the unique features of scenic spots themselves, but also needs the support, operation and care of the government, enterprises and farmers in order to have a strong sustainable development, stand out in the fierce market competition, promote the development of local economy.

\subsection{Regional Characteristic Culture Is the Main Body}

Beipiao is a big city with strong performance in many fields, such as historical culture, farming-reading culture and geomantic culture. In the long history, Beipiao used to be the center of regional culture. Here has a long history and is known as the "world's first bird fly up, the first flower bursting", It is an important geological museum for the process and development of earth life and is also an important cultural birthplace in Northwest Liaoning, the hongshan culture, three yan culture and liao culture. Many emperors, generals and dignitaries have left touching legends here (such as the story of qin Shihuang's flattening of Daheishan, the story of Emperor Qianlong's watching ironwood blossom ["The Legend of Pingdingshan", Beipiao Folk Literature (The First Volume), Beipiao Municipal Bureau of Culture (unpublished), 2007: 299]), which has created profound local cultural deposits. At the same time, Beipiao is also a tourist base to experience the landscape and regional culture outside the Great Wall and the intersection of the farming culture and the grassland culture. As a result, more than 900 sites of various types are preserved in Beipiao's beautiful mountains 
and rivers and famous historical sites, At the same time, it has diversified folk resources and legendary beautiful legends, which is the meeting point of understanding grassland culture and farming culture, and has the reputation of "the hometown of Chinese folk characteristic art" and "the hometown of chili".

The preservation of rich historical and cultural resources has become an important carrier for the existence of Beipiao leisure agriculture. The tourism resources in Bepiao can be divided into natural scenery, such as Daheishan Forest Park and Baishi Reservoir. Religious landscape and historical relics characteristics, such as Huining Temple, Huiyuan Temple, etc. Museums of natural ecology in scientific research tourism, such as Sihetun Fossil Museum; Industrial and agricultural tourism, such as Beipiao Guanshan Well, Taiji well, etc. According to legends and celebrities, they can also be divided into former residences, such as yinzhannaxi's former residence and memorial hall; and red tourism, such as Daheishan, Heichengzi, quanjuyong, mengyingying, etc.

\subsection{The Development and Operation of Enterprises Have Boosted the Regional Influence of Leisure Agriculture}

Modern company management and management system is the internal power of sustainable development of leisure agriculture. The development of leisure agriculture needs to operate in accordance with the business development model and accepts the risk test of the market. It belongs to the "self-financing type". The rise of leisure agriculture industry needs smart entrepreneurs and groups to help it develop and move towards the way of modern company operation and management. For example, Ruyi Mountain Villa established in Ma Youying makes full use of the local Mongolian culture, wine culture and food culture, and makes great efforts in the design of projects such as viewing, entertainment and picking, etc., so that its leisure agriculture experience tour has formed the miracle effect of "It has been open to the outside world for less than three years and has been well-known" (Xia, 2019).

\subsection{The Government Led the Development of the Breadth and Depth of Leisure Agriculture}

The economy of Beipiao city is relatively backward, the leisure agriculture starts late, the development level is low, and the system of all aspects is not perfect. Therefore, the leading role of the government cannot be ignored. Focusing on government policies can renew the public's awareness of the weakness of leisure agriculture, and at the same time make use of the "judgment" power in their hands to formulate industry norms and help train professional management personnel (Yang, 2020). From today's development, there are not only include flower watching, rafting, picking, skiing and other conventional leisure agricultural projects in Beipiao at all seasons. Moreover, due to the migration of wild geese (Swan) and other migratory birds, seasonal changes of water flow and other reasons, a large-scale leisure agricultural tourism industrial belt in towns has 
been formed, including Shangyuan, Osaka, changheying, zhangjiying, Mayouying.

\section{The Main Problems Existing in the Development of Leisure Agriculture in Beipiao City}

There are a lot of problems in the development of leisure agriculture in Beipiao City, including the development space of grade, function and layout. In order to achieve better development of leisure agriculture, it is necessary to recognize the root causes of these problems.

\subsection{The Overall Planning of the Scenic Spot Is Not Perfect, There Are Many Similar Projects Which Are in Different Levels}

The leisure agriculture in Beipiao is still in its initial stage, and the scenic spot lacks scientific basis in overall planning. It shows that the project functions are relatively simple and lacks independent innovation ability. In the development, it usually shows that the scenic spot projects are similar, small in scale, uneven in grade and lack of brands. Most of the leisure agriculture and regional leisure products in Beipiao are of the same quality and type with the regional scope (the affected area is generally Liaoning province or more widely in Beijing, Tianjin, Hebei, Liaoning and Inner Mongolia), and there is a serious lack of connotation, [according to Yuan Lixin, Shi Shuqiang, Qi Xin, etc., the development status, problems and Countermeasures of leisure agriculture in Liaoning Province pointed out that by the end of 2017, the main types of leisure agriculture in Liaoning Province were: farmhouse, leisure farm, leisure agricultural park, folk village, etc., and the development of leisure agriculture was still in the "spontaneous" stage, and $93.99 \%$ of leisure agricultural parks have no cultural tourism projects.] In particular, it did not highlight the advantages of Beipiao, such as the advantages of "the hometown of Chinese folk art" and "hometown of pepper". Liaomei, pepper, folk calligraphy, painting, paper cutting, fossils and other local characteristic projects are not well integrated with the tourist attractions for collaborative development, which is shown as a small piece, a small segment of the development state, which reduces its own characteristics. In addition, the infrastructure between each piece and segment is not perfect, and the supporting hotel is not of high grade, which seriously affects the consumption needs of tourists.

\subsection{The Government's Guidance Is Not Strong and the Pursuit of "Profit" Is Obvious}

For specific commercial operation, the government adheres to the principle of non-interference, but it is responsible to supervise the number of a single commercial operation site, otherwise it will not only result in the waste of limited resources, but also generate improper vicious competition. Most of the developers of leisure agriculture in Beipiao are farmers or township enterprises in the mode of cooperation, and tend to pursue interests. Under the influence of prof- 
its, there are many projects of the same grade and similar type in leisure agriculture in Beipiao area, such as the development of farmhouse projects. If the government does not strengthen guidance at the right time, driven by interests, it is easy to form a hostile competition situation, which seriously affects the healthy development of leisure agriculture industrialization.

\subsection{Lack of Network Talents and Awareness of Brand Effect in Agricultural Network Development}

Talent is the key in agricultural development industrialization, especially in the era of rapid network development. The development of network needs high-end talents, and it is urgent for leisure agriculture to develop vocational education and skill education in the region to adapt to the development of network. It will enable sightseeing agriculture to complete the whole process of display and sale directly on the Internet. Network has become a platform to undertake the development of leisure agriculture industry, talent is the necessary intellectual support. However, in the agricultural industrialization of Beipiao region, there is a shortage of specialized talents who know technology, can manage and can sell on the Internet. Nowadays, college students in Beipiao region seldom return to Work in Beipiao after graduation, and the health of leisure agriculture industrialization lacks some talents engaged in agricultural network. Older people are not familiar with network brand publicity, marketing and sales or lack of novel ideas, which makes it difficult to attract young people's attention. Therefore, the protection awareness of the existing agricultural brands is weak, which restricts the development of leisure agriculture to a certain extent.

\section{Suggestions on the Innovative Development of Leisure Agriculture in Beipiao City}

The development process of leisure agriculture needs to transform relatively rich agricultural resources into productive capital with high income expectation, which is also the basic driving force of leisure agriculture in Beipiao area. In this process of development, "we need to have historical patience". We need to break the level of decentralized management of small farmers with backward technology, accelerate the unified social security system and supervision system between urban and rural areas, promote equity and finance to tie up the countryside, and further serve the countryside (Li, 2017). The countermeasures and Suggestions for agricultural industrialization development at the present stage are as follows:

\subsection{Reasonably Planning Layout, Combining Governance and Management}

With the continuous development of modern leisure agriculture and rural tourism, relevant departments should make scientific and reasonable planning layout and make overall arrangements according to local conditions. Governance requires the support of management and application of science and technology. 
The development of agricultural planting in Beipiao area is most restricted by topographical factors. Agricultural production is not easy, and the uneven land has made farmers suffer greatly. In the development of leisure agriculture, we should try our best to combine local development with market, support leading enterprises in agricultural product processing, guide leading enterprises, improve agricultural market, and strengthen infrastructure construction to reflect the government's guarantee function of serving agricultural industrialization. At the same time, we should pay attention to the rights and interests of the land involved in management. A series of policies such as state subsidies, land acquisition and leasing, as well as contracts involving economic interests, have also made farmers more interested in land, increasing their enthusiasm for participation. The land interest is growing. Solving these problems can promote the stimulating effect of market regulation on leisure agriculture and promote the healthy development of a regional industry.

\subsection{Develop Scientifically and Harmoniously, Establish and Improve the Guarantee Mechanism of Agricultural Industrialization}

Improving the security mechanism of leisure agriculture is the general trend of current agricultural development and the inevitable development of rural urbanization. With the development of socialist market economy, rural development has been brought up to the level of urbanization, farmers also want to enjoy the life and treatment of "city residents", agricultural development can't wait. Therefore, the development of leisure agriculture needs and supermarkets, farmers market, network connection, at the same time, rural areas need corresponding industrial mechanism such as intermediary organizations, social service organizations, as well as application of science and technology, information transmission, medical services are gradually in line with the city, otherwise the rural economy is difficult to develop, agricultural industrialization is difficult to establish. The government needs to transfer the methods of urban management to the countryside, so that the pace of agricultural industrialization will be greatly accelerated. In fact, with the popularization of information and technology, farmers know a lot of knowledge. The government creates a good development atmosphere for agricultural industrialization, and guides the development of leisure agriculture in land requisition, tax collection, farmer training, etc., which is the realization of agricultural industrialization.

\subsection{Constantly Strengthen Farmers Information Training, Enhance Their Confidence in Agricultural Development and Promote the Brand of Leisure Agriculture}

Agricultural development needs confident farmers, which is the fundamental driving force to support the development of agricultural industrialization. No one is willing to engage in agriculture. No matter how good it is, it is empty talk. Farmers in Beipiao believe in ecological civilization and hope to make use of 
agricultural production to become rich. They are very concerned about recycling agriculture and promoting agriculture through science and technology, and they are all enthusiastic about it. Therefore, they should improve the information literacy of farmers. It is very important to train them on computer technology, communication technology and electronic technology, so that they can understand the relevant information websites, quickly query the information they need, collect and disseminate information in time, and effectively solve the problem of information service. They are encouraged to actively promote local tourism projects and attract more tourists based on the Internet plus platform. Combined with the advantages of local agricultural production, it is necessary to cultivate regional brands, carry out online marketing of agricultural and sideline products and handicrafts, and realize the wide spread of characteristic tourism culture. In the development of leisure agriculture industrialization, Beipiao's millet, potato, donkey meat, honey and other well-known organic agricultural products certification, geographical indication certification and National Geographic Indication certification have been established, In order to improve the popularity of agricultural products and make efforts on well-known brands, leisure agriculture can achieve gratifying results from industrial positioning, brand building and market development.

With the increase of market demand, the mode of integrating rural tourism with sightseeing agriculture is becoming more and more popular. But at this institute, stage of development, leisure agriculture has the characteristics of homogeneity in the national development, individual character is not obvious, therefore, are universal, encountered difficulties and problems in the future in the study of leisure agriculture development research will pay more attention to their own characteristics, from the current development of leisure agriculture in ruyi hill coming north ticket individual characteristics, but needs to be deep understanding and further research, observational study.

On the whole, the development of Beipiao leisure agriculture requires local governments, enterprises and farmers to seek for comprehensive, coordinated and sustainable development. The government needs to adjust the relationship between them to promote the comprehensive, coordinated and sustainable development of modern leisure agriculture and rural tourism (Odan, 2018). Therefore, from the study of characteristics, it can be seen that rural tourism and sightseeing agriculture will be a new, distinctive and sustainable highlight in the transformation and development of Beipiao leisure agriculture.

\section{Conflicts of Interest}

The authors declare no conflicts of interest regarding the publication of this paper.

\section{References}

Li, X. (2017). In Chaoyang City Research Emphasis on Poverty Alleviation Work Conscientiously Implement the Jinping General Secretary about Important Indicator Spirit 
Our Practical Work Resolutely Fight Poverty Intense Study.

http://www.lnrc.com.cn/contents/531/3424.html

Odan (2018). Research on the Development Strategy of Leisure Agriculture and Rural Tourism Integration. Contemporary Tourism, 6, 173.

Xia, K. X. (2019). Chen Zhigang, General Manager of Ruyi Villa in Beipiao City. Beipiao City Daily.

Yang, L. (2020). Thinking on the Construction of Modern Agricultural System in Liaoning Province. Rural Economy, 1, 31. 